\title{
Reducing drinking in concurrent problem alcohol and illicit drug users: an impact story
}

\author{
Jan Klimas ${ }^{1,2^{*}}$, Helen Tobin ${ }^{2}$, Catherine-Anne Field ${ }^{3}$, Clodagh SM O'Gorman ${ }^{4,5}$, Liam G Glynn ${ }^{6}$, Eamon Keenan ${ }^{7}$, \\ Jean Saunders ${ }^{4}$, Gerard Bury ${ }^{2}$, Colum Dunne ${ }^{4}$, Walter Cullen ${ }^{2}$ \\ From The Core Outcome Measures in Effectiveness Trials (COMET) Initiative \\ Calgary, Canada. 20-21 May 2015
}

\section{Background}

One out of three people who receive methadone in primary care drink in excess of the recommended limits. This poses significant risk to their health, especially to their liver; it complicates their care and increases risk of relapse.

\section{Objective}

To inform addiction treatment in primary care with respect to psychosocial interventions to reduce drinking in concurrent problem alcohol and illicit drug users, by: exploring the experience of (and evidence for) psychosocial interventions, developing and evaluating a complex intervention to improve implementation. Evaluation of the intervention tested core feasibility and acceptability outcomes for patients and providers.

\section{Methods}

A Cochrane review found only four studies. Having inconclusive evidence, we interviewed 28 patients, 38 physicians and nurses. Patient interviews informed development of a national clinical practice guideline, as well as design and outcomes of the evaluation project. Feasibility outcome measures included recruitment, retention, completion and follow-up rates, as well as satisfaction with the intervention. Secondary outcome was proportion of patients with problem alcohol use at the follow up, as measured by Alcohol Use Disorders Identification Test.

\section{Results}

Information from the Cochrane review and the qualitative interviews informed an expert panel consultation which developed clinical guidelines for primary care.

\section{Conclusions}

The guideline became part of a complex intervention to support the uptake of psychosocial interventions by family physicians; the intervention is currently evaluated in a pilot controlled trial. Two new alcohol education programmes were created as a response of the community to the problem and a lack of specialist support services for patients with dual dependencies. Both Coolmine Therapeutic Community and the Community Response Agency run a 10-week group that specifically seeks to include people with dual dependencies, from methadone programmes.

\section{Authors' details \\ 'British Columbia Centre for Excellence in HIV/AIDS, St. Paul's Hospital, Vancouver, Canada. ${ }^{2}$ School of Medicine and Medical Science, University College Dublin, Dublin, Ireland. ${ }^{3}$ Health Promotion School of Health Sciences, National University of Ireland, Galway, Ireland. ${ }^{4}$ Graduate Entry Medical School, Faculty of Education and Health Sciences, University of Limerick, Limerick, Ireland. ${ }^{5}$ Department of Paediatrics, Mid-Western Regional Hospital, Limerick, Ireland. ${ }^{6}$ Department of General Practice, National University of Ireland, Galway, Ireland. ${ }^{7}$ Addiction Services, Health Service Executive, Dublin, Ireland.}

Published: 24 November 2015

doi:10.1186/1745-6215-16-S3-P11

Cite this article as: Klimas et al.: Reducing drinking in concurrent problem alcohol and illicit drug users: an impact story. Trials 2015 16(Suppl 3):P11.

\footnotetext{
* Correspondence: jan.klimas@ucd.ie

'British Columbia Centre for Excellence in HIV/AIDS, St. Paul's Hospital,

Vancouver, Canada

Full list of author information is available at the end of the article
} 